\title{
Prazepam Measurement
}

National Cancer Institute

\section{Source}

National Cancer Institute. Prazepam Measurement. NCI Thesaurus. Code C139080.

The determination of the amount of prazepam present in a sample. 